\title{
Anisotropy and compression/tension asymmetry of PP containing soft and hard particles and short glass fibers
}

\author{
A. M. Hartl ${ }^{1}$, M. Jerabek ${ }^{2 *}$, R. W. Lang $^{1}$ \\ ${ }^{1}$ Institute of Polymeric Materials and Testing, Johannes Kepler University Linz, Altenberger Strasse 69, 4040 Linz, \\ Austria \\ ${ }^{2}$ Borealis Polyolefine GmbH, St.-Peter Str. 25, 4021 Linz, Austria
}

Received 17 November 2014; accepted in revised form 19 February 2015

\begin{abstract}
Polypropylene (PP) composites are used in a wide range of structural applications. Except for fiber reinforced PP, most PP particle composites are commonly considered to be isotropic or at least quasi-isotropic. In this paper, however, the anisotropy of several PP composites containing soft (rubber) and hard (talc) particles and glass fibers is characterized in detail in terms of the material microstructure as well as the resulting mechanical properties in monotonic tensile and compressive experiments. The microstructural investigations showed that all composites displayed a certain surface-core layer structure of distinctly different orientation patterns and with a higher degree of orientation in the surface layer. Also in mechanical testing an anisotropic behavior was observed with the degree of anisotropy being more pronounced in tension than compression. Moreover, the compression/tension asymmetry also strongly depends on filler type and orientation.
\end{abstract}

Keywords: polymer composites, mechanical properties, anisotropy, polypropylene

\section{Introduction}

The property profile of polypropylene homo and hetero (multi-phase) systems can be tailored to meet a wide range of demands with regard to processing (e.g. dimensional stability), thermal and mechanical properties (impact vs. stiffness). Combined with cost advantages over other polymers, polypropylenes (along with polyethylenes) therefore hold the highest market share among all plastics. By addition of fillers and reinforcements, typically engineering and specialty plastics markets, such as for example in the automotive industry, increasingly opt for tailormade polypropylene (PP) solutions. In terms of mechanical property optimization, the resistance against impact and deformation (i.e. stiffness) are of prime importance in many structural components [1]. The impact behavior is commonly modified by copolymerization with ethylene units or by rubber toughening via compounding [2]. The stiffness in turn can be increased by the addition of stiff, mineral particles like talc (most widely used), mica and calcium carbonate, which also reduce the cost of the composite [1]. In the higher price segment, short and long glass fibers offer the possibility of simultaneously increasing the toughness and stiffness of brittle PP. In the context of this paper the term 'filler' is used to encompass all of these different constituents. More recently, also so called ternary or hybrid composites have gained increasing attention in the scientific community, opting for a synergistic effect of the three component materials (e.g. PP with fibers and rubber particles or PP with hard particles and rubber particles) on properties and/or cost reduction [3-12].

During compounding and especially during final part shaping in injection molding and extrusion pro-

\footnotetext{
${ }^{\text {*Corresponding author, e-mail: michael.jerabek@borealisgroup.com }}$ (C) BME-PT
} 
cessing, the spatial arrangement of the fillers is controlled by the local conditions of the melt flow. Differences in viscosity and/or high aspect ratios of the filler can lead to a preferential orientation in melt flow direction. More precisely, the resulting shape and/or spatial distribution and the orientation of the filler is a function of the conditions during processing (e.g. temperature and shear rate), the composition of the composite, the interface interaction and in the case of rubber additions - the ratio of rubber and matrix viscosity [13-16]. Especially for discontinuous fiber reinforced polymers numerous efforts have been undertaken to analytically and numerically investigate and describe the orientation distribution by means of melt flow analysis [17-20]. In most shell like parts, a pronounced layer structure in terms of preferred orientations develops during melt injection. In this context it is well known, that typically particles and fibers in tool wall vicinity are oriented mainly in or at small angles to the flow direction due to shear gradient effects and mostly perpendicular (again with angle variations) to the flow direction in the core layer due to extensional flow effects $[14,17,18,21,22]$. The orientation of the filler in turn has an effect on the preferred crystallization direction due to trans-crystallization effects on the filler surface, displaying higher values for higher degrees of particle orientation [21, 23, 24]. Yet, for talc and calcium carbonate filled PP, Pukánszky et al. [25] showed that the anisotropy introduced by the particle and not that of the polymer crystals governs the mechanical behavior.

While the orientation dependent properties of fiber reinforced polymers has been the topic of numerous investigations [18, 26-28], rather little data has been published for other types of particle reinforced composites typically with smaller aspect ratios. Exemplary for rubber, Wang et al. [14] found a strong dependence of the impact properties on the orientation of the rubber. For talc, Díez-Gutiérrez et al. [29] reported a pronounced anisotropic behavior in dynamic mechanical analysis of PP talc composites.
Furthermore, Kunkel et al. [30] characterized the anisotropy in tensile tests and considered this in the material model for FEM analysis.

Thus, the focus of the research reported in this paper was to characterize the anisotropy in tension and compression experiments along with the resulting compression/tension asymmetry of a variety of PP composites. Various types of soft and hard particle and short glass fiber composites were injection molded with equivalent processing parameters (similar thermal history) into a specially designed tool, which has proven to introduce a high and uniform fiber orientation distribution (FOD) in short glass fiber (sgf) reinforced PP. Consequently, the tensile and compressive stress-strain behavior of these composites with filler orientation in and perpendicular to the loading direction were characterized. Emphasis was placed on the anisotropic and asymmetric tension/compression behavior in terms of initial deformation behavior ( $E$-modulus and Poisson's ratio), volumetric deformation evolution (Poisson's ratio trends) and ultimate failure properties (strength values).

\section{Experimental}

\subsection{Materials and specimens}

In addition to the neat PP matrix, a total 5 composites with this PP matrix were studied in the present paper. These include (1) composite filled with $32 \mathrm{~m} \%$ soft particle (rubber, PP-R32), (2) and (3) composites filled with soft and hard particle with two different ratios of filler content (rubber and talc platelets, PP-R $(\mathrm{m} \%)-\mathrm{T}(\mathrm{m} \%))$ and (4) and (5) short glass fiber reinforced composites with $32 \mathrm{~m} \%$ glass fibers with different fiber length distributions (PP-sgf32-1 and sgf32-2). In Table 1, details on the material designation of the PP/filler compounds along with information on the composition and the filler shape and fiber aspect ratio after injection molding are provided. The two sgf materials differ in their aspect ratio by about 30\%. The PP-sgf32-1 material was the commercial Fibremod $^{\mathrm{TM}}$ GD301FE grade, whereas all

Table 1. Material designation of the PP based materials along with information on the composition and the filler shape and fiber aspect ratio

\begin{tabular}{|l|l|c|c|c|c|c|}
\hline \multicolumn{2}{|c|}{ Composite types: PP filled with } & Rubber & \multicolumn{2}{c|}{ Rubber and talc } & \multicolumn{2}{c|}{ Short glass fiber } \\
\hline Material designation and filler characteristics & PP-R32 & PP-R27-T10 & PP-R12-T32 & PP-sgf32-1 & PP-sgf32-2 \\
\hline Rubber & content shape & $32 \mathrm{w} \%$ & $27 \mathrm{w} \%$ & $12 \mathrm{w} \%$ & & \\
\hline & & \multicolumn{3}{|c|}{ elliptic shape } \\
\hline Talc & content shape & $10 \mathrm{w} \%$ platelet & $32 \mathrm{w} \%$ platelet & & \\
\hline Glass fibers & content aspect ratio & & & & $32 \mathrm{w} \% 23$ & $32 \mathrm{w} \% 32$ \\
\hline
\end{tabular}




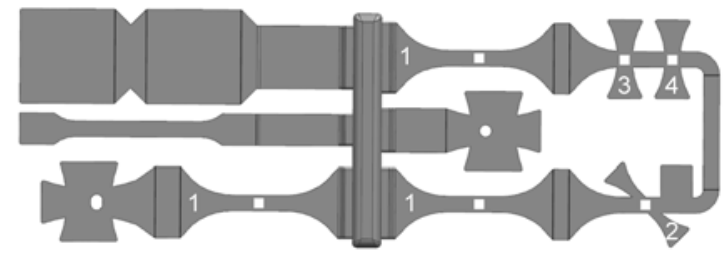

Speciment types used in this study:

$0^{\circ}-$ specimens $(1) ; 45^{\circ}-$ specimens $(2) ; 90^{\circ}-$ specimens $(3,4)$;

Figure 1. Tool used for injection molding of composites with differing particle orientation (thickness of all specimen sections $2 \mathrm{~mm}$ )

other composites are experimental grades (all supplied by Borealis Polyolefine GmbH; Linz, Austria). A novel quasi-unidirectional (UD) tool, originally developed to obtain specimens with a wide range of glass fiber orientations (for further details see [31]) was used for injection molding (see Figure 1). To enhance and maximize the degree of shear-flow induced orientation, the thickness of the tool cavity is $2 \mathrm{~mm}$. The tool thus allows to directly mill out the specimens for 0 and $90^{\circ}$ testing used in this investigation.

\subsection{Characterization of morphology and microstructure}

For the characterization of the microstructure, scanning electron microscopy (SEM) investigations, wide angle X-ray scattering (WAXS) experiments and $\mu$-CT measurements were conducted. In terms of sample preparation for SEM, the melt flow direction (MFD) - specimen thickness $(x-z)$ plane of the $0^{\circ}$ specimens filled with rubber and talc were first cut by a cryo-microtome, consequently etched by nheptane and $\mathrm{KMnO}_{4}$, respectively, and analyzed. While the rubber particles displayed sufficient contrast in the standard imaging mode based on secondary electrons to both the matrix and also the talc particles, backscattered electrons were detected in order to assess the orientation of the talc particles. The aspect ratio (major/minor length) in melt flow direction (MFD, for the $0^{\circ}$ specimens this corresponds to the testing direction) of the rubber particles and the orientation angle in MFD with respect to the tool wall of the talc particles were automatically evaluated by an image processing Matlab based software script based. As quantitative measure for the talc particle orientation, the Herman's orientation factor $f_{\mathrm{H}}$ was calculated based on the measured orientation angle $\phi$ according to Equation (1) [32, 33]:
$f_{\mathrm{H}}=\frac{3 \cdot\left(\cos ^{2} \phi\right)-1}{2}$

with an $f_{\mathrm{H}}$ value of 1 and -0.5 indicating perfect orientation in and perpendicular to the MFD (and correspondingly the testing direction), respectively.

Furthermore, WAXS was used to assess the crystalline orientation and the corresponding Herman's orientation factors (for details see [34]). The orientation of the glass fibers in the sgf reinforced PP material was assessed in a Nanotom (GE Phoenix|X-ray, Wunstorf, Germany) $\mu$-CT device at a resolution of $2 \mu \mathrm{m}$ voxel edge length. Scan parameters were set such that contrast and data quality was optimized. The 3D data was analyzed by an automatic software pipeline (for further details see $[31,35]$ ).

\subsection{Mechanical testing and data reduction}

All mechanical tests were conducted at a strain rate of $0.001 \mathrm{~s}^{-1}$ and at $23^{\circ} \mathrm{C}$. The tensile testing was performed on a universal screw-driven test machine of the type Zwick Z020 (Zwick GmbH \& Co. KG; Ulm, Germany). In compression testing of plastics according ISO 604, the load should be introduced by compression plates and specimen thickness should be $4 \mathrm{~mm}$. As discussed above, a high degree of crystalline, particle and fiber orientation is only achievable for specimen with smaller specimen thickness (due to increased shear flow contribution). Thus in this investigation compressive loads were introduced by highly aligned clamping jaws on an Instron ElectroPuls E10000 (Instron, Norwood, USA). The clamping length was set to $9 \mathrm{~mm}$ in order to avoid failure by buckling. Indeed, no out of plane displacement was observed and all specimens failed in a shear mode (as also cross-checked via digital image correlation (DIC); see below).

For all tension and compression tests, the longitudinal force, the full-field strain on the front surface $(x$ and $y$ direction) and also on the side surface of the specimen ( $x$ and $z$ direction) were measured by means of DIC with two cameras (ARAMIS 12M by GOM, Gesellschaft für optische Messtechnik mbH; Braunschweig, Germany). Both cameras were triggered at exactly the same time instances. This additional test effort was undertaken as for transversely anisotropic materials the strains in $y$ and $z$ direction differ. Further details as to the DIC test method and data reduction including the evaluation of true stresses and strains [36] are given elsewhere. 


\section{Results and discussion}

An overview of the effect of the different fillers on the deformation and failure behavior in terms of tensile elastic modulus versus tensile strength along with a first indication of the variation of mechanical properties due to particle orientation is depicted in Figure 2. For comparison the neat PP matrix properties are also illustrated in the diagram. As discussed above, by addition of glass fibers the modulus and strength of PP can be significantly increased. In the following subsections, first the crystalline and filler orientation is assessed and described as basis for further discussions. Subsequently, the anisotropy (as defined by the ratio of the $0^{\circ}$ specimen to $90^{\circ}$ specimen properties) in terms of modulus and strength in tension and compression and the anisotropy in the compression/tension asymmetry (as represented by the ratio of compressive to tensile strength) is discussed. The differences in the deformation behavior on a micro-scale are then analyzed in terms of Poisson's ratio trends in the final subsection.

\subsection{Morphology and microstructure}

On a nanoscopic fine scale, even the neat matrix itself may be considered as a composite of rigid crystalline lamellar and soft amorphous interlamellar regions. The orientation of the crystals was characterized by WAXS for selected specimens, and the Herman's orientation factors of the lamellas were deduced and are provided in Table 2. Since the orientation of the fillers has a more pronounced effect on the mechanical properties (as mentioned above),

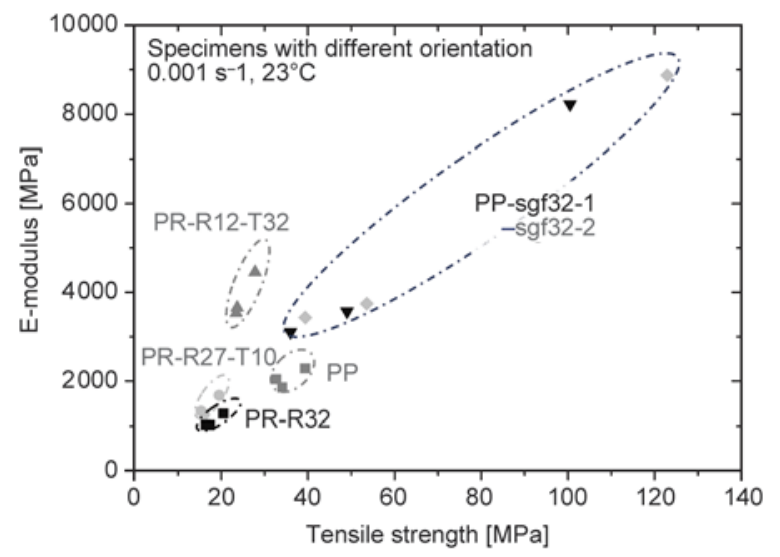

Figure 2. Overall illustration of mechanical anisotropy of all materials investigated in terms of tensile $E$-modulus versus tensile strength; the elliptical envelopes for the various materials indicate the property range covered by orientation effects as measured with $0^{\circ}$ (highest values), $45^{\circ}$ and $90^{\circ}$ (lowest values) specimens further focus is on the orientation of (1) the rubber, (2) the talc particles and (3) the short glass fibers. Regarding the first, the aspect ratio of the rubber with the major axis in melt flow direction and the minor axis in specimen thickness direction was taken as a parameter for the orientation, with a value of 1 (spherical) characterizing the unoriented state and values $>1$ (elliptical) an orientated state with a primary orientation in MFD. In good agreement with literature observations (e.g. [16] for rubber, [17, 18] for sgf polymers), a five layer structure consisting of two outer skin layers at the specimen surface, two surface layers positioned beneath the outer skin and a central core layer was detected across the specimen thickness direction (see Figure 3). The filler orientation reflects the local conditions of shear flow in surface near regions (higher degree of orientation) versus elongational flow in the core region (lower degree of orientation). By adding talc, the overall viscosity is increased. On a local scale, however, the shear rate in the inter-particle region is increased and due to the non-Newtonian behavior of the matrix the viscosity decreases [37]. These two effects could possibly be the cause for the higher degree of orientation of the rubber particles observed in the talc filled PP matrix compared to the neat PP matrix.

In an analogous manner, the talc particles also display a decreasing degree of orientation towards the specimen center, as represented by the Herman's orientation factor. This trend is more pronounced for the material with the higher talc content (see Figure 4). These findings are in good agreement with results presented by Pukánszky et al. [25], who also reported a decreasing talc orientation with increasing filler content for PP talc composites.

Turning now to the short glass fiber reinforced materials PP-sgf32-1 and -2, the first entry of the orientation tensor $\mathrm{A}_{11}$ is shown in Figure 5a again as a function of the specimen thickness. In this context, values for $A_{11}$ of 1 and 0 , respectively, indicate perfect fiber orientation in and perpendicular to the MFD. Apart from the skin layer (first $200 \mu \mathrm{m}$ ), only a slightly higher degree of orientation is observed in the surface layer than in the core layer. It should be noted, however, that the injection molding tool used was explicitly designed to reduce the layer structure and to achieve a high average fiber orientation across the entire specimen thickness (for further details see [31]). For the same reason, the local degree of fiber orientation (and hence the average degree of fiber 

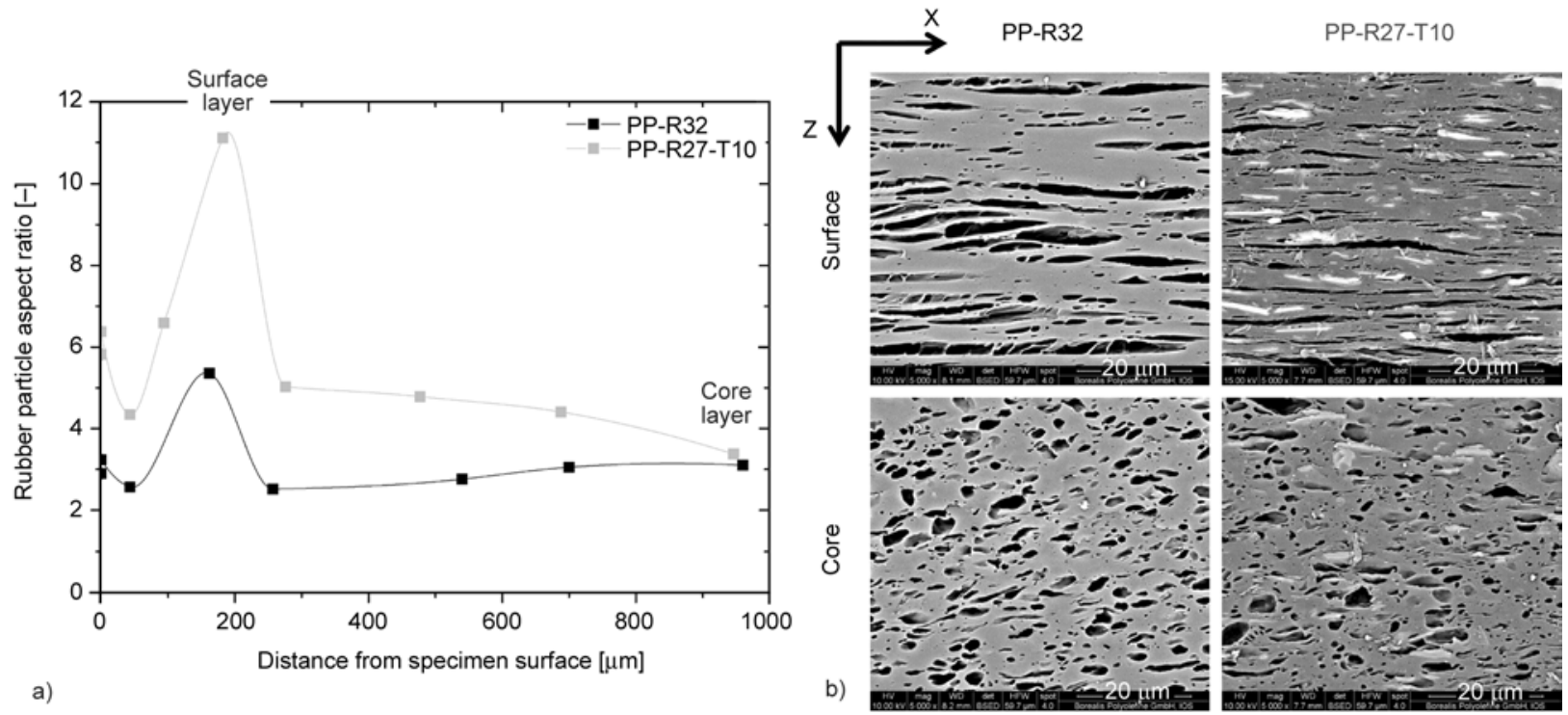

Figure 3. Rubber particle aspect ratio (indicative of orientation effects) as a function of the distance from the specimen surface (covering half of the specimen thickness) comparing PP-R32 and PP-R27-T10 (a), and corresponding SEM pictures taken from the surface and core layer, respectively, with dark regions representing the rubber particles (b)
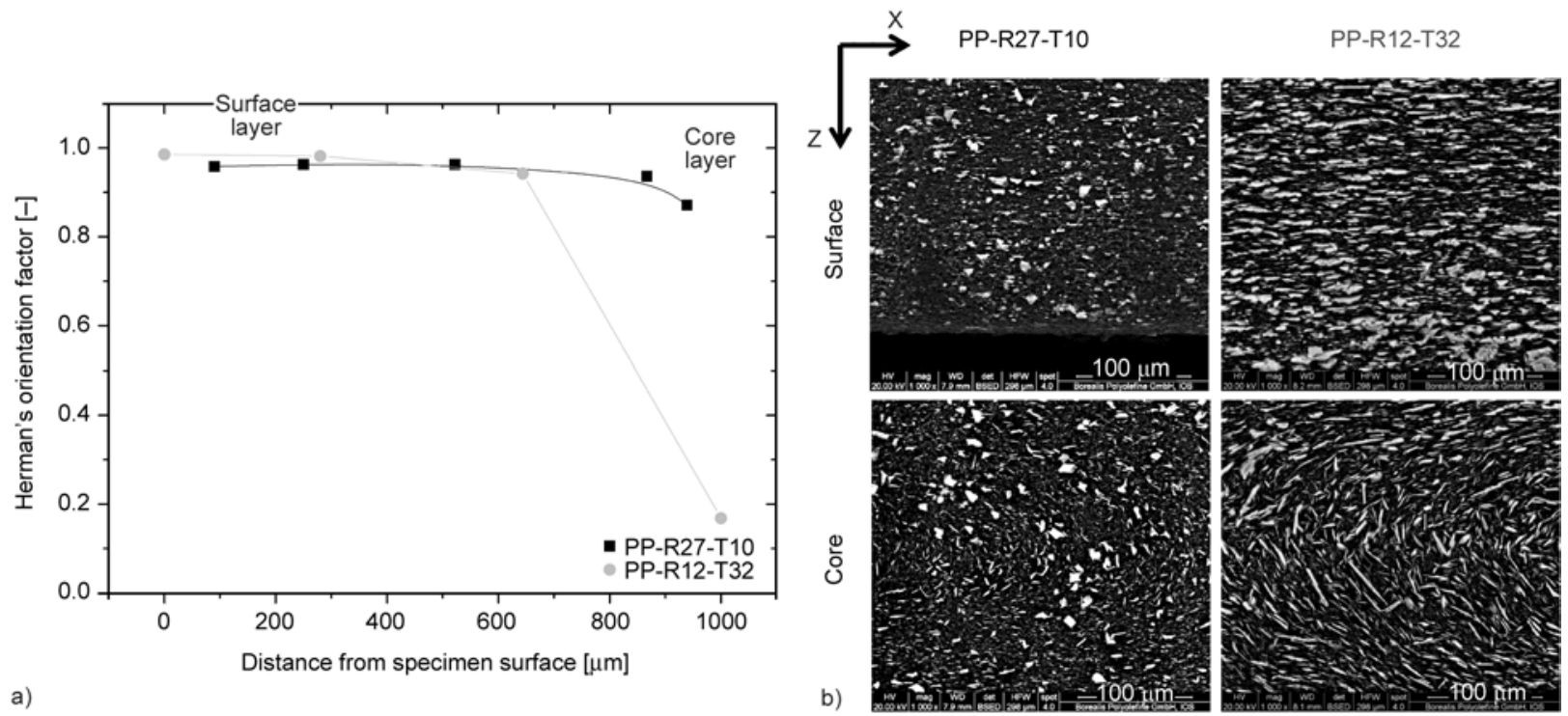

Figure 4. Herman's orientation factor of the talc particles as a function of the distance from the specimen surface (covering half of the specimen thickness) comparing PP-R27-T10 and PP-R12-T32 (a) and corresponding SEM pictures taken from the surface and core layer, respectively (b); bright platelets represent talc particles

orientation; compare Table 2) also hardly depends on the fiber aspect ratio. Moreover, in Figure 5b, a schematic illustration of the individual fiber arrangements in a given measurement volume is provided along with the average orientation tensor and the graphical representation of the orientation ellipses (for further details see $[38,39]$ ).

Table 2. Herman's orientation factors of the different material constituents

\begin{tabular}{|c|c|c|c|c|c|c|c|}
\hline \multirow{2}{*}{\multicolumn{2}{|c|}{\begin{tabular}{|c|}
\multicolumn{2}{|c|}{ Composite types } \\
Material designation and Herman's factors
\end{tabular}}} & \multirow{3}{*}{$\begin{array}{l}\mathbf{P P} \\
0.014 \\
\end{array}$} & \multirow{3}{*}{\begin{tabular}{|c|} 
Soft particle \\
PP-R32 \\
0,007 \\
\end{tabular}} & \multicolumn{2}{|c|}{ Soft and hard particle } & \multicolumn{2}{|c|}{ Short glass fiber } \\
\hline & & & & PP-R27-T10 & PP-R12-T32 & PP-sgf32-1 & PP-sgf32-2 \\
\hline \multirow{3}{*}{ WAXS (crystals) } & $f_{\mathrm{a}}$ & & & 0.001 & -0.019 & & \\
\hline & $f_{\mathrm{b}}$ & -0.295 & -0.188 & -0.158 & -0.156 & & \\
\hline & $f_{\mathrm{c}}$ & 0.309 & 0.181 & 0.157 & 0.175 & & \\
\hline SEM (talc) & $f$ & & & 0.91 & 0.8 & & \\
\hline$\mu-\mathrm{CT}$ & $f$ & & & & & 0.79 & 0.82 \\
\hline
\end{tabular}



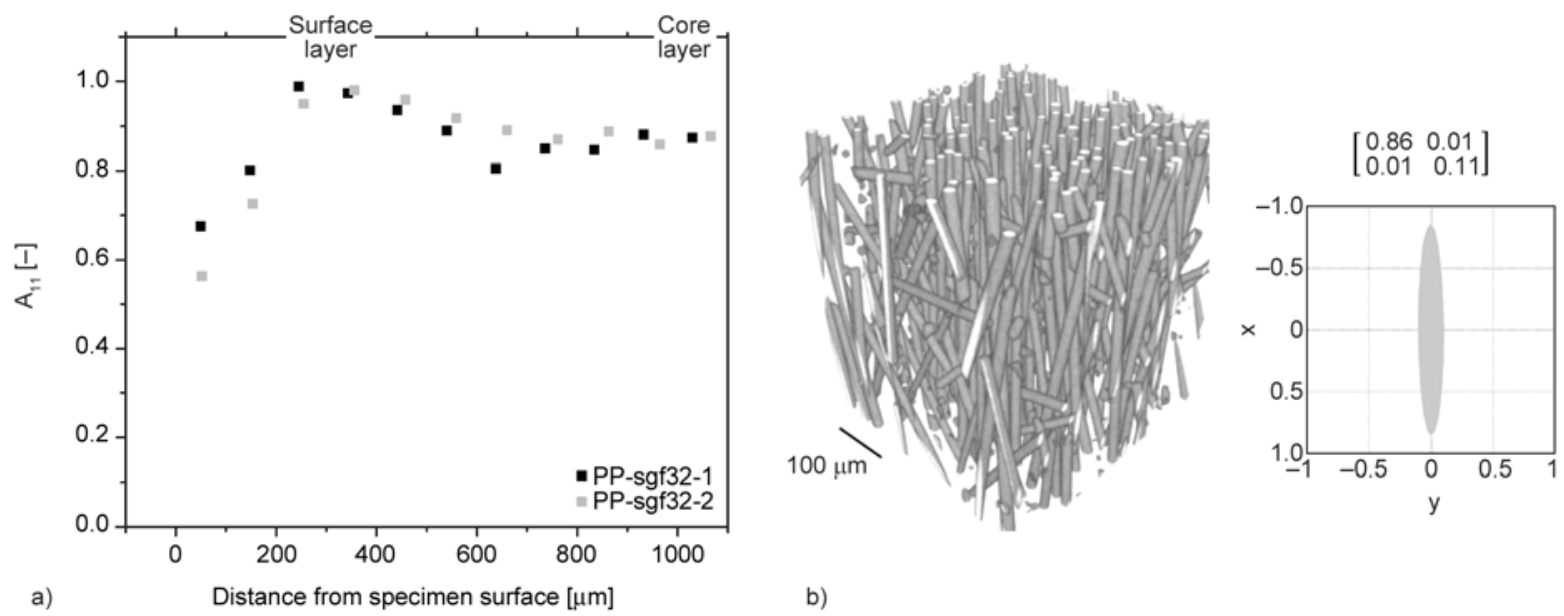

b)

Figure 5. First entry of the orientation tensor $\left(A_{11}\right)$ of the sgf reinforced $P P$ as a function of the distance from the specimen surface (covering half of the specimen thickness) comparing PP-sgf32-1 and PP-sgf32-2 (a) and a schematic illustration of all fibers in a segment of the measurement volume and the orientation tensor and ellipses of PP-sgf32-1 (b)

Overall anisotropy in the stress-strain behavior in tension and compression

The tensile and compressive stress-strain behavior of PP-R32, PP-R12-T32 and PP-sgf32-2 in and perpendicular to the main melt flow direction (MFD), which reflects the main particle orientation, is depicted in Figure 6. Strain softening behavior is observed for PP-R 32 for the $0^{\circ}$ compressive and the $90^{\circ}$ tensile specimens and more pronounced for all PP-R12-T32 specimens. In both material cases, strain softening can possibly be attributed to debonding of the particles [40, 41]. In tension, the PP-sgf32-2 specimens break in a brittle manner without major ductile deformation. In compression, the $0^{\circ}$ specimens fail in a shear mode without major ductile deformation, whereas the $90^{\circ}$ specimens display a highly ductile behavior. For all materials an anisotropic behavior displaying higher values in direction of particle orientation was found, both in tension and compression. In a very general sense and as expected, the

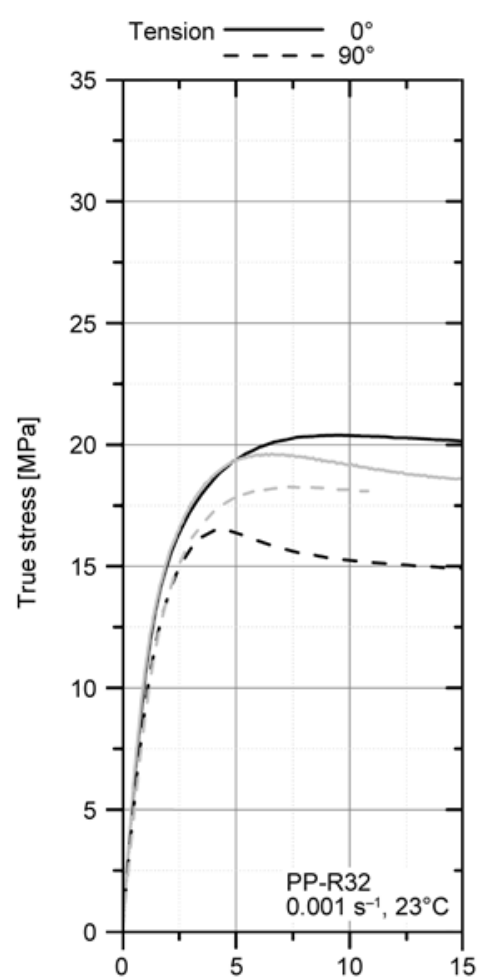

a)

$$
\text { a) }
$$

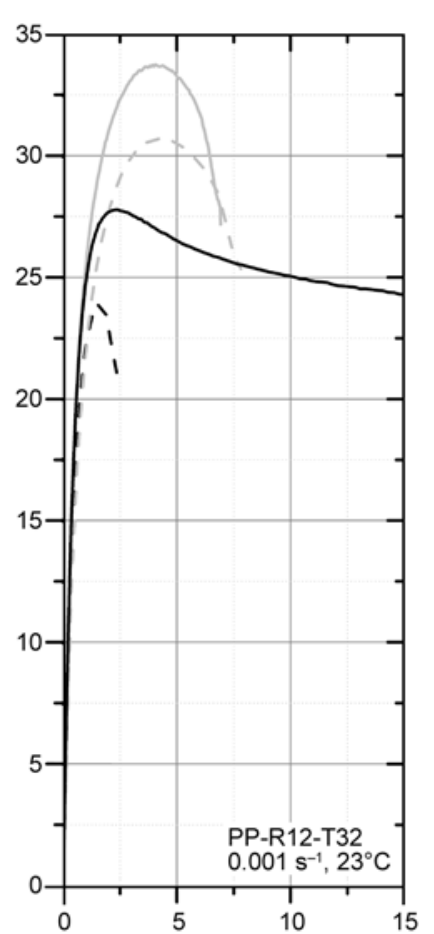

b)

Local strain [\%]

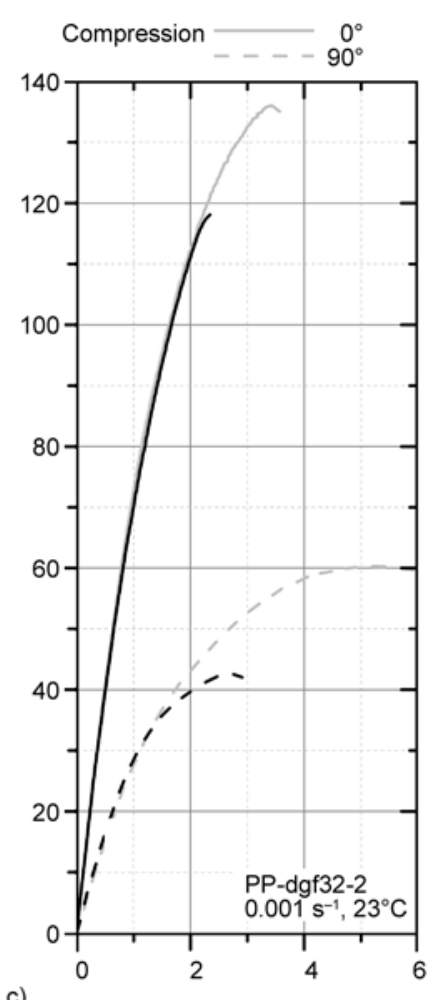

c)

Figure 6. Stress-strain trends in compression and tension of PP-R32 (a); PP-R12-T10 (b) and PP-sgf32-2 (c) 
degree of anisotropy is seen to increase with increasing filler stiffness and filler aspect ratio. When comparing the stress-strain behavior in compression and tension for the various materials and their orientation states, the following is observed. Apart from the $0^{\circ}$ PP-32R specimens, for which the tensile and compressive behavior is rather similar, the ultimate properties (i.e. yield or failure stress) in compression are significantly higher than in tension. Furthermore, for all materials, the difference between compressive and tensile strength is apparently larger for the $90^{\circ}$ specimens than for the $0^{\circ}$ specimens.

\subsection{Anisotropy in the deformation behavior: E-modulus}

The anisotropy in terms of the ratio of the tensile Emodulus of the $0^{\circ}$ specimens and the $90^{\circ}$ specimens is depicted in Figure 7, a value of 1 corresponding to isotropic behavior. Even the neat matrix, which is typically considered to be at least quasi-isotropic, reveals higher modulus values in MFD by about $10 \%$ due to some molecular orientation. As expected, the degree of anisotropy is higher for the PP composites. For soft and hard particle systems the $0^{\circ}$ specimens exhibit a higher modulus by approximately $25 \%$ (anisotropy ratio of 1.25 ). Interestingly, among the two PP-R-T composites, the specimen with higher talc content shows a slightly lower anisotropy $(22 \%$, anisotropy ratio of 1.22), which may be attributed to the lower degree of talc particle orientation, as evidenced by the SEM investigations described above. Significantly higher values for the modulus anisotropy ratio of about 2.5 were found for the PP-sgf materials, with slightly higher values for the fibers with higher aspect ratio, as expected. For comparison Figure 7 also contains corresponding data for the anisotropy ratio of a perfectly oriented, continuous fiber reinforced PP with a fiber content of $58 \mathrm{~m} \%$ (designated as PP-cgf58) from the literature [42]. Due to the perfect alignment, the higher fiber content and the continuous fibers (corresponding to a quasiinfinite aspect ratio), a value of 7.5 was deduced for the anisotropy ratio.

To analyze the effects of the two parameters degree of fiber orientation and fiber length more quantitatively, the experimental tensile modulus values of the PP-sgf materials are plotted in Figure 8 (top) as a function of the length of the vector of the orientation ellipses in testing direction $p^{0}$ (designated as and corresponding to an averaged fiber orientation prob-

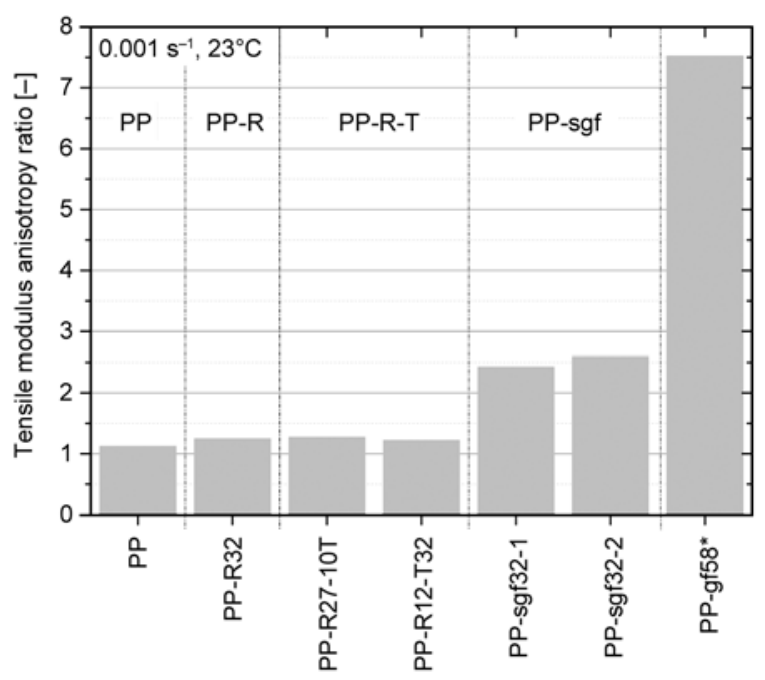

Figure 7. Anisotropy ratios (i.e. ratio of the $0^{\circ}$ and $90^{\circ}$ modulus) of tensile modulus values for the different PP based materials (data * from [42])

ability in testing direction). The latter parameter was used in earlier studies, in which a linear correlation was found for the modulus (and strength) as a function of $p^{0}$, thus allowing for the extrapolation of properties to a perfect fiber orientation in the testing direction $\left(p^{0}=1\right)$ and perpendicular to the testing direction $\left(p^{0}=0\right)$. The anisotropy ratio of these extrapolated modulus values in Figure 8 (top) correspond to the ideal, maximum modulus anisotropy ratio. In a next step these ratios were plotted in Figure 8 (bottom) as a function of the weight average fiber length and compared to theoretical modulus calculations according to the model proposed by Cox-Krenchel assuming a fiber content of $32 \mathrm{w} \%$ (for details on this model see [43]). Two observations may be made. First, there is rather good agreement between our experimental based values and the CoxKrenchel prediction. Second, looking at the CoxKrenchel prediction, a value of about 6 may be reached for the modulus anisotropy ratio with increasing fiber length for fiber lengths approaching continuous fibers. This actually is rather close to the experimental value of 7.5 for PP-cgf58 depicted in Figure 7, the difference being explicable due to the higher fiber content in the latter case.

It should be mentioned, that in terms of the modulus anisotropy ratio very similar results to those described for tensile loading conditions were found for compressive loading. This is not surprising, as it is known that in the small strain regime, in which modulus determination takes place (i.e. $0.05-0.25 \%$ ), tensile and compressive moduli are essentially equal. 

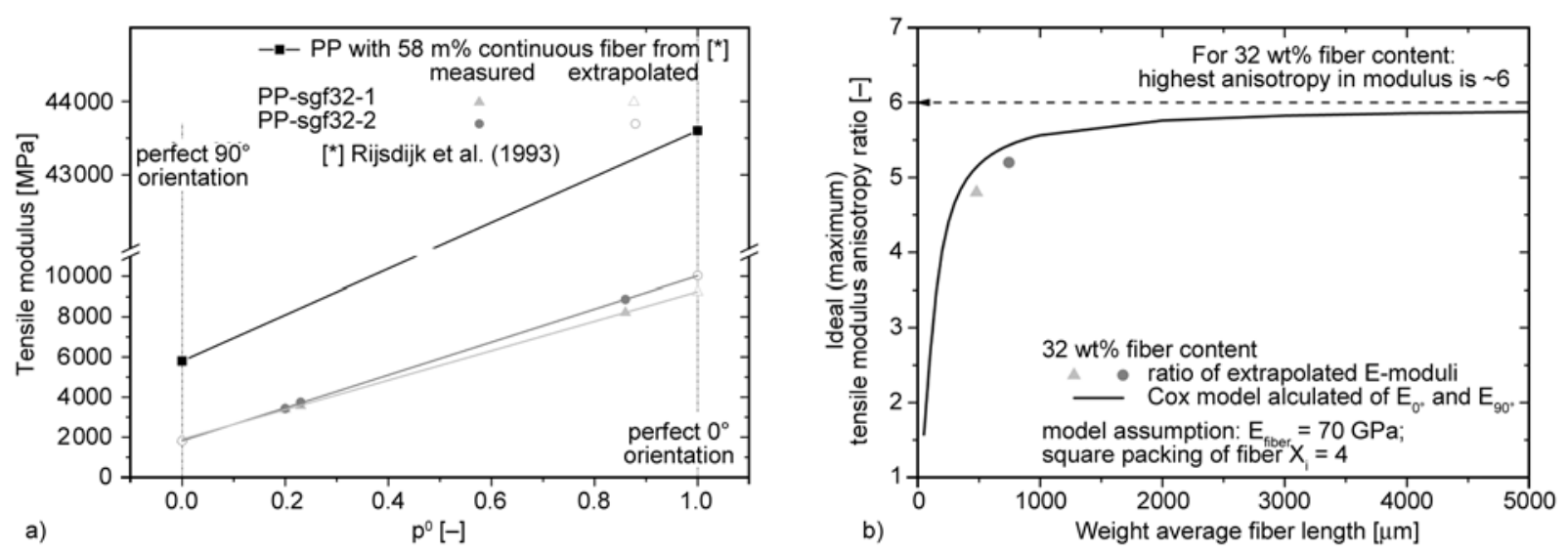

Figure 8. Fiber orientation and fiber length dependent $E$-modulus (a) and fiber length dependence of anisotropy in PP with $32 \mathrm{~m} \%$ glass fibers (b)

\subsection{Anisotropy in the deformation behavior: Poisson's ratio}

In isotropic materials, the volumetric deformation (volume strain, $\varepsilon_{\mathrm{v}}$ ) is directly related to the true longitudinal strain $\left(\varepsilon_{\mathrm{t}, \mathrm{x}}\right)$ and a single Poisson's ratio value $v_{\mathrm{xy}}$. In contrast, in anisotropic materials an effective Poisson's ratio $v_{\text {eff }}$ characterizing volume strain effects can be defined which must account for two directional Poisson's ratios $\left(v_{\mathrm{xy}}\right.$ and $v_{\mathrm{xz}}$, see Equations (2)-(4) [44]:

$$
\begin{aligned}
& \varepsilon_{\mathrm{v}}=v_{\mathrm{eff}} \varepsilon_{\mathrm{t}, \mathrm{x}} \\
& v_{\mathrm{eff}}=1-v_{\mathrm{xy}}-v_{\mathrm{xz}} \\
& v_{\mathrm{xy}, \mathrm{xz}}=\left|\frac{\varepsilon_{\mathrm{yz} 2}-\varepsilon_{\mathrm{yz} 1}}{\varepsilon_{\mathrm{x}, 2}-\varepsilon_{\mathrm{x} .1}}\right|
\end{aligned}
$$

Therefore, increasing values for the directional Poisson's ratio result in a decreasing effective Poisson's ratio, which in turn implies a decrease in volume strain. Values for the directional Poisson's ratio, $v_{\mathrm{xy}}$

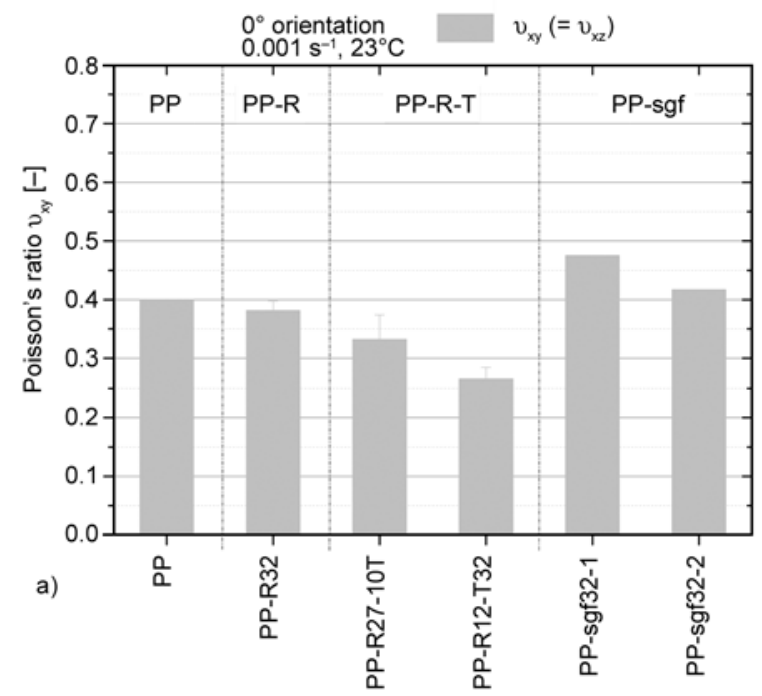

and $v_{\mathrm{xz}}$, and the effective Poisson's ratio in the linear-viscoelastic regime (i.e. 0.05-0.25\%) are shown for all materials investigated in Figure 9 and Figure 10.

Starting first with the $0^{\circ}$ specimens in Figure $9 a$, the deformation behavior was found to be transversely isotropic for all cases investigated with equivalent values for $v_{\mathrm{xy}}$ and $v_{\mathrm{xz}}$. The directional Poisson's ratios decrease with increasing filler content for the PP-R and PP-R-T materials resulting in increasing values of effective Poisson's ratio and hence (dilatational) volume strain (see Figure 10). This observed decrease in the Poisson's ratio of the PP-R material in the linear-viscoelastic region is remarkable (Figure 9a), as based on a rule-of-mixture assumption the values should increase (Poisson's ratio of $\sim 0.4$ and $\sim 0.5$ for the pure matrix and the rubbery phase, respectively). In rubber materials the bulk modulus is much larger than the $E$-modulus and shear modulus due to the high Poisson's ratio. When a specimen

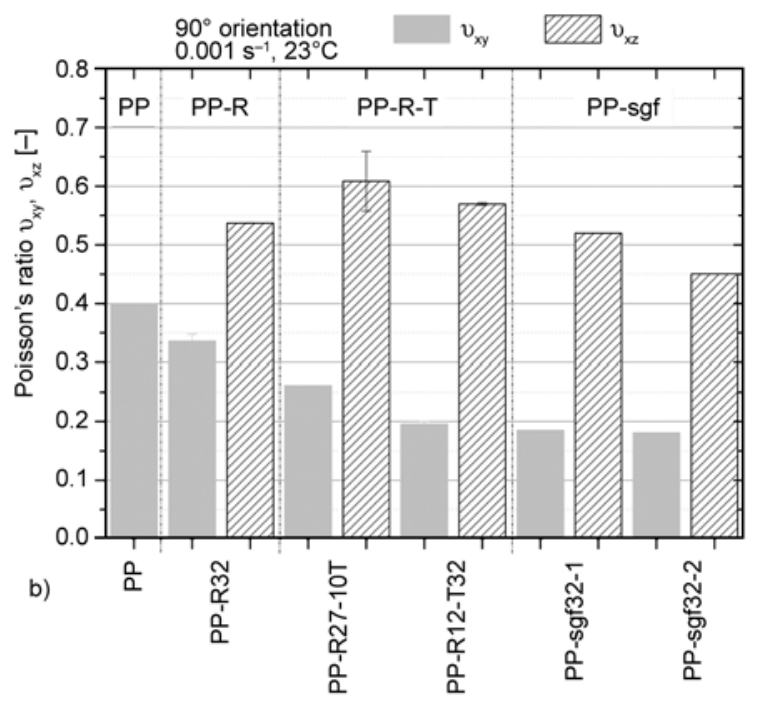

Figure 9. Tensile, directional Poisson's ratios for $0^{\circ}$ (a) and $90^{\circ}$ (b) specimens of the different PP based materials 
is loaded in tension, the embedded elongated rubber particles and/or the matrix/rubber interphase are subjected to tri-axial stress and thus behavior is governed by the bulk modulus. The high bulk modulus of the rubbery phase may thus be the reason for the inhibited contraction in $y$-direction. By an increased addition of talc, the directional Poisson's ratio is further decreased. This can be attributed to the low Poisson's ratio of talc ( $\sim 27$ according [45]). The highest directional Poisson's ratio values were measured for the PP-sgf materials. This in turn corresponds to the lowest effective Poisson's ratio and volume strain values (see Figure 10), which may be caused by the high constraint of the matrix phase imposed by the fibers.

Regarding the $90^{\circ}$ specimens (see Figure 9b), the two directional Poisson's ratio values $v_{\text {xy }}$ and $v_{\text {xz }}$ differ significantly. For this case, the contraction in the direction of particle orientation ( $y$-direction) is increasingly inhibited with increasing particle stiffness and particle aspect ratio. Therefore, the directional Poisson's ratio $v_{\mathrm{xy}}$ is lowest for PP-sgf32-2. The inhibited deformation in $y$-direction is compensated by an increased deformation in $z$-direction (specimen thickness), with values for the Poisson's ratio $v_{\mathrm{xz}}$ ranging from about 0.45 to 0.6 for all materials. When combining these two directional Pois-

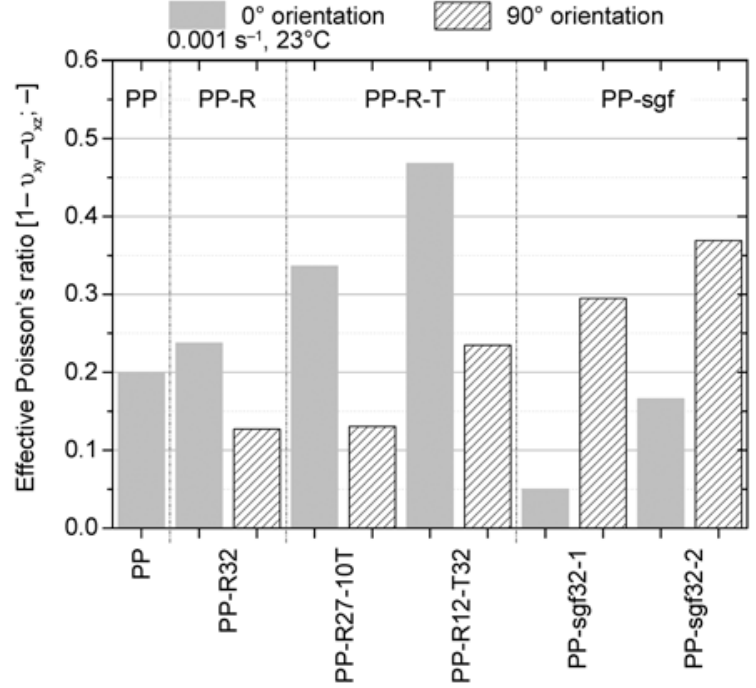

Figure 10. Effective tensile Poisson's ratio for $0^{\circ}$ and $90^{\circ}$ specimens of the different PP based materials

son's ratio values to the effective Poisson's ratio (see Figure 10), increasing values are observed for specimens containing fillers with increasing particle stiffness and particle aspect ratio. Interestingly, for the soft and hard particle filled PP, the effective Poisson's ratio and hence the (dilatational) volume strain is larger for the $0^{\circ}$ than for the $90^{\circ}$ specimens, while the opposite trend is observed for PP-sgf materials. In Figure 11, the two Poisson's ratio values $v_{\mathrm{xy}}$ and $v_{\mathrm{xz}}$ are plotted as a function of the longitudinal strain

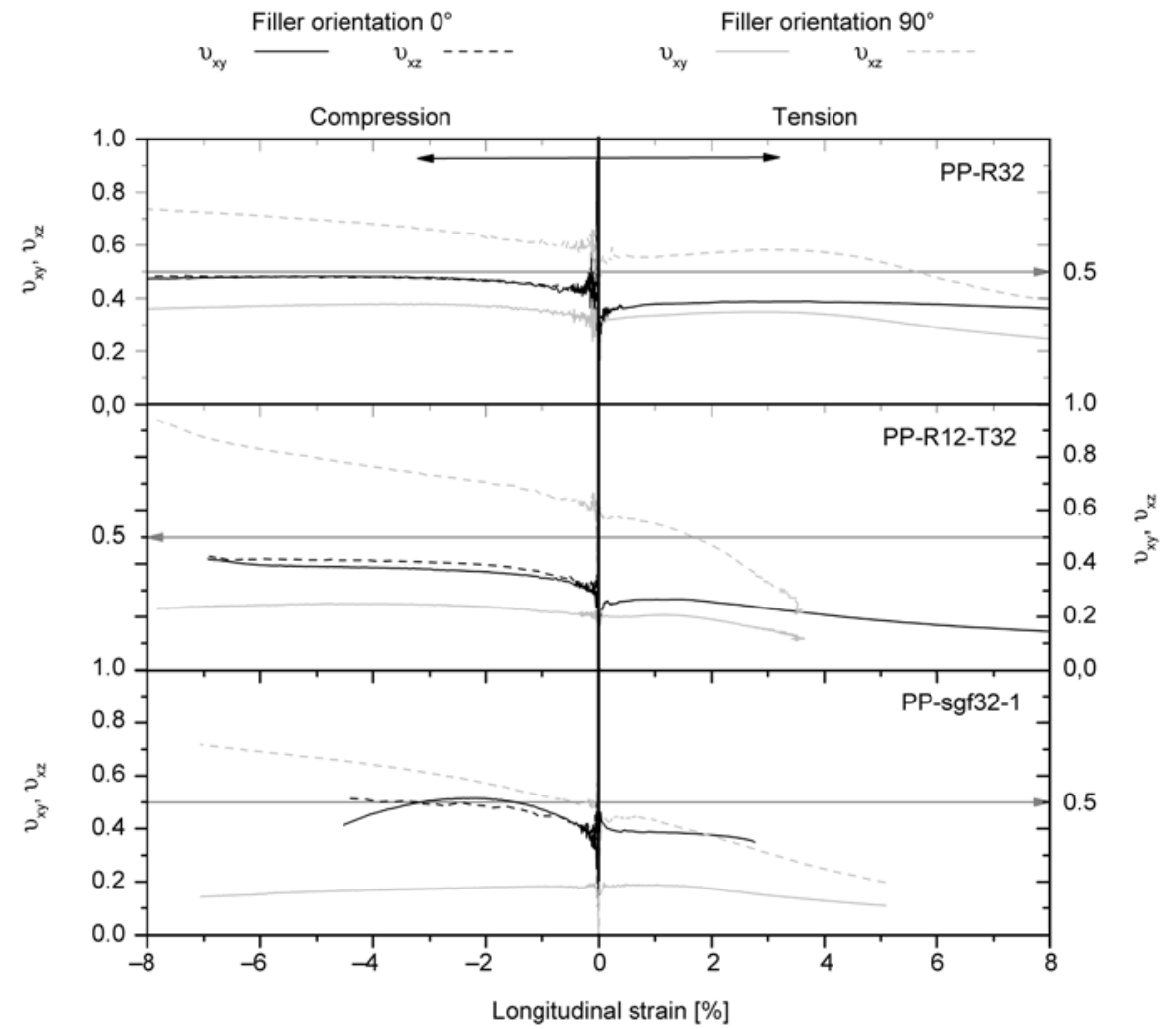

Figure 11. Tensile and compressive Poisson's ratio as a function of longitudinal strain for PP-R32, PP-R12-R32 and PP-sgf32-1 
for the tensile and compressive loading, and for the $0^{\circ}$ and $90^{\circ}$ specimen, respectively. As expected, the two Poisson's ratio trends of the $0^{\circ}$ specimens are equivalent, due to the transverse isotropy. For the $90^{\circ}$ specimens, however, $v_{\mathrm{xz}}\left(\varepsilon_{\mathrm{x}}\right)$ is significantly larger than $v_{\mathrm{xy}}\left(\varepsilon_{\mathrm{x}}\right)$ as the transverse strain in $y$-direction is hindered by the filler orientation in this direction. Similar to observations for $E$-moduli (see above), in the linear visco-elastic regime, the Poisson's ratio in tension and compression are essentially equivalent (within measurement inaccuracy). At higher values of tensile deformation, the Poisson's ratio values decrease with increasing longitudinal strain. This trend is more pronounced for $v_{\mathrm{xz}}\left(\varepsilon_{\mathrm{x}}\right)$ and $90^{\circ}$ specimens. As discussed above, this in turn corresponds to an increase in volume strain values which can be correlated to the onset of void formation [44]. In contrast, in compression the Poisson's ratio values increase and the volume strain decreases with increasing longitudinal strain, corresponding to shear governed local deformation. In terms of absolute values, it should be noted, that $v_{\mathrm{xz}}\left(\varepsilon_{\mathrm{x}}\right)$ in tension displays values above 0.5 for some $90^{\circ}$ specimens, with even higher values obtained in compression.

\subsection{Anisotropy and compression/tension asymmetry in the failure behavior}

In terms of the anisotropy of ultimate properties (i.e. tensile and compressive strength), similar trends, as discussed above for the small strain regime (i.e. $E$-modulus), can be observed (see Figure 12). Inter-

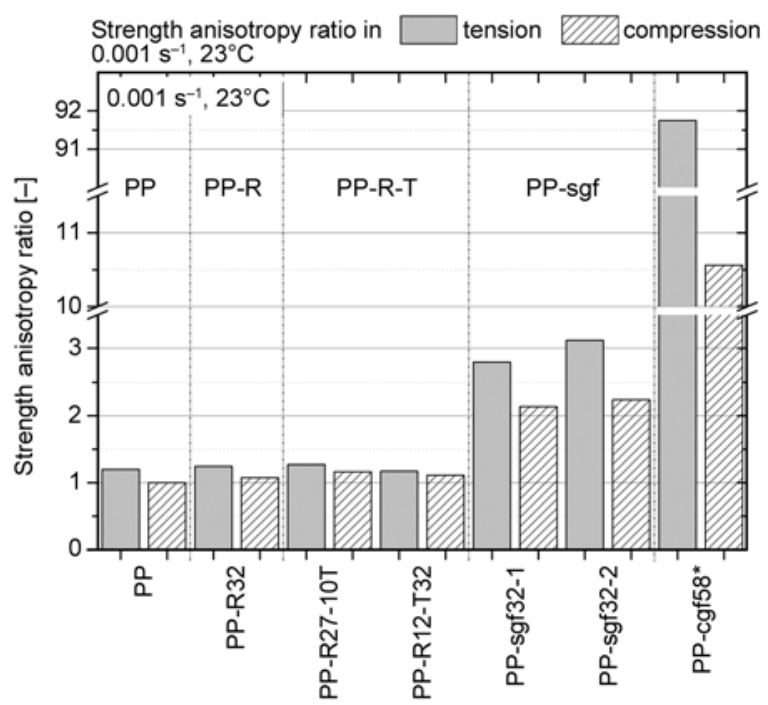

Figure 12. Anisotropy ratios (i.e. ratio of the $0^{\circ}$ and $90^{\circ}$ strength) of tensile and compressive strength values for the different PP based materials (data* from [42]) estingly, when comparing tension and compression, the anisotropy ratio is always lower in compression with larger differences for short and continuous glass fiber reinforced materials. This phenomenon can be related to differences in the damage evolution, especially associated with the significant formation of voids in tension vs. shear yielding governed deformation in compression of the $90^{\circ}$ specimens. Similar differences in the microscopic deformation modes under tension and compression also occur in the other PP based materials (compare also Poisson's ratio trends discussed above).

Turning to the compression/tension asymmetry, values for the compressive/tensile strength ratio are plotted for the various materials in Figure 13. Clearly, the asymmetry of the $90^{\circ}$ specimens is always notably higher than of the corresponding $0^{\circ}$ specimens. For neat PP, the difference in the compressive/ tensile strength ratio of the $0^{\circ}$ and $90^{\circ}$ specimen is a consequence of the isotropic behavior in compression testing (equivalent yield stress values of $0^{\circ}$ and $90^{\circ}$ specimens). Apparently, differences in the molecular and crystalline orientation of $0^{\circ}$ and $90^{\circ}$ specimens play only a minor role in governing the compressive behavior of PP. Compared to the neat matrix, the soft and hard particle filled PP composites exhibit lower values of compression/tension asymmetry. As discussed above for the Poisson's ratio effects, this may again possibly be a consequence of the incompressibility and the corresponding high bulk modulus of the rubber filler. Following this argument, the decreasing rubber content may be the cause for the

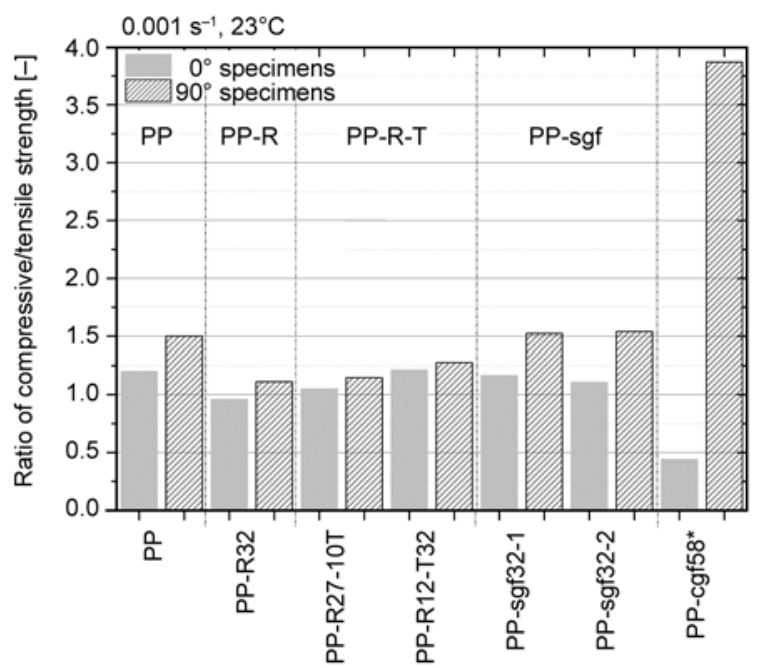

Figure 13. Asymmetry as represented by the ratio of the compressive to the tensile strength for the $0^{\circ}$ and $90^{\circ}$ specimens of the different composites (data * from [42]) 
observed increasing compression/tension asymmetry of the PP-R-T materials.

Finally, for glass fiber reinforced materials, the compression/tension asymmetry of the $0^{\circ}$ specimen decreases and of the $90^{\circ}$ specimen increases with increasing fiber length. With respect to the $0^{\circ}$ specimens, longer fibers are more prone to buckling at equivalent matrix stiffness values which results in lower compressive strength values. Regarding the $90^{\circ}$ specimens, and as already stated above, the significantly higher compression/tension asymmetry may be attributed to changes in deformation mechanisms from tensile to compressive testing. In the tensile loading mode, major void formation is likely for particles/fiber with perpendicular orientation and especially with increasing aspect ratio. In sharp contrast, shear deformation and shear failure dominates the compressive loading mode.

\section{Conclusions}

An overall objective of the present paper was to comprehensively analyze the deformation modes of various PP based materials (including neat PP, rubber toughened PP-R, rubber and talc filled PP-R-T, and short glass fiber reinforced PP-sgf) as affected by the orientation and the loading mode (tension vs. compression). Using a specially designed multi-tool for injection molding of specimens with high soft and/or hard particle or fiber orientation, a special focus was on investigating mechanical anisotropy effects and compression/tension asymmetry effects in the small strain (visco-elastic) and ultimate failure regime. The following results were obtained:

- Via the novel UD tool for producing injection molded specimens, a high degree of orientation could be achieved in all of the materials investigated.

- Testing of $0^{\circ}$ and $90^{\circ}$ specimens revealed significant but various degrees of anisotropic behavior for all materials in terms of $E$-modulus, Poisson's ratio (incl. Poisson's ratio evolution) and strength.

- Anisotropic behavior was found to be more pronounced in tension than in compression.

- The compression/tension asymmetry strongly depends on the filler type and orientation, exhibiting higher values for $90^{\circ}$ specimens.

- An analysis of the evolution of Poisson's ratio values with increasing longitudinal strain allows for conclusions on the volumetric deformation behav- ior. The higher compression/tension asymmetry of the $90^{\circ}$ specimens is considered to be a result of the larger scale voiding in tension, a phenomenon which is essentially suppressed in compression.

Of paramount practical importance, these results may serve as basis for the development of more accurate material models which not only account for the anisotropic behavior, but also for the orientation dependent compression/tension asymmetry.

\section{Acknowledgements}

This research was undertaken within the bilateral project 1.02 'Heterogeneous Polymer Compounds - PP Compounds and Magneto-Elastomers' of the COMET K-Project 'Advanced Polymeric Materials and Process Technologies (APMT)' (http://apmt/jku.at). The project is funded as part of the COMET program of the Austrian Research Promotion Agency (FFG) and is supported by the Federal Ministry for Transport, Innovation and Technology (BMVIT), Federal Ministry of Economy, Family and Youth (BMWFJ) and the Upper Austrian Government (Research Department). The authors thank Borealis AG (Linz, Austria) for fruitful discussions, providing the specimens as well as conducting the WAXS and SEM analysis, and the University of Applied Sciences Upper Austria, Wels Campus (Wels, Austria) for conducting the $\mu$-CT experiments. Also the support of Paul Freudenthaler (JKU, Linz, Austria) in conducting the mechanical tests is gratefully acknowledged.

\section{References}

[1] Kissel W. J., Han H., Meyer J. A.: Polypropylene: Structure, properties, manufacturing processes and applications. in 'Handbook of polypropylene and polypropylene composites' (ed.: Harutun K. G.) Marcel Dekker, Hoboken, 10-27 (2003).

[2] Liang J. Z., Li R. K.: Rubber toughening in polypropylene: A review. Journal of Applied Polymer Science, 77, 409-417 (2000).

DOI: $10.1002 /($ SICI) $1097-4628(20000711) 77: 2<409:$ : AID-APP18>3.0.CO;2-N

[3] Denac M., Musil V., Šmit I.: Polypropylene/talc/SEBS (SEBS-g-MA) composites. Part 2. Mechanical properties. Composites Part A: Applied Science and Manufacturing, 36, 1282-1290 (2005).

DOI: $10.1016 /$ j.compositesa.2005.01.011

[4] Fu S-Y., Lauke B.: Fracture resistance of unfilled and calcite-particle-filled ABS composites reinforced by short glass fibers (SGF) under impact load. Composites Part A: Applied Science and Manufacturing, 29, 631-641 (1998).

DOI: 10.1016/S1359-835X(97)00111-5

[5] Fu S-Y., Xu G., Mai Y-W.: On the elastic modulus of hybrid particle/short-fiber/polymer composites. Composites Part B: Engineering, 33, 291-299 (2002). DOI: $10.1016 / \mathrm{S} 1359-8368(02) 00013-6$ 
[6] Hartikainen J., Hine P., Szabó J. S., Lindner M., Harmia T., Duckett R. A., Friedrich K.: Polypropylene hybrid composites reinforced with long glass fibres and particulate filler. Composites Science and Technology, 65, 257-267 (2005).

DOI: 10.1016/j.compscitech.2004.07.010

[7] Huang C., Li R. K., Wu C., Duan Z.: Stiffness behaviour of injection moulded short glass fibre/impact modifier/polypropylene hybrid composites. Journal of Materials Processing Technology, 96, 48-52 (1999).

DOI: 10.1016/S0924-0136(99)00251-4

[8] Laura D., Keskkula H., Barlow J. W., Paul D. R.: Effect of rubber particle size and rubber type on the mechanical properties of glass fiber reinforced, rubber-toughened nylon 6. Polymer, 44, 3347-3361 (2003). DOI: 10.1016/S0032-3861(03)00221-0

[9] Tjong S. C., Xu S. A., Mai Y. W.: Impact fracture toughness of short glass fiber-reinforced polyamide 6,6 hybrid composites containing elastomer particles using essential work of fracture concept. Materials Science and Engineering: A, 347, 338-345 (2003).

DOI: 10.1016/S0921-5093(02)00609-3

[10] Tjong S. C., Xu S-A., Li R. K-Y., Mai Y-W.: Mechanical behavior and fracture toughness evaluation of maleic anhydride compatibilized short glass fiber/SEBS/polypropylene hybrid composites. Composites Science and Technology, 62, 831-840 (2002).

DOI: $10.1016 / \mathrm{S} 0266-3538(02) 00037-4$

[11] Wang W., Tang L., Qu B.: Mechanical properties and morphological structures of short glass fiber reinforced PP/EPDM composite. European Polymer Journal, 39, 2129-2134 (2003).

DOI: 10.1016/S0014-3057(03)00157-5

[12] Zhang L., Li C., Huang R.: Toughness mechanism of polypropylene/elastomer/filler composites. Journal of Polymer Science Part B: Polymer Physics, 43, 11131123 (2005).

DOI: $10.1002 /$ polb.20395

[13] Wang C., Su J. X., Li J., Yang H., Zhang Q., Du R. N., Fu Q.: Phase morphology and toughening mechanism of polyamide 6/EPDM-g-MA blends obtained via dynamic packing injection molding. Polymer, 47, 31973206 (2006).

DOI: $10.1016 /$ j.polymer.2006.03.012

[14] Wang Y., Zhang Q., Na B., Du R., Fu Q., Shen K.: Dependence of impact strength on the fracture propagation direction in dynamic packing injection molded PP/EPDM blends. Polymer, 44, 4261-4271 (2003).

DOI: 10.1016/S0032-3861(03)00366-5

[15] Fellahi S., Favis B. D., Fisa B.: Morphological stability in injection-moulded high-density polyethylene/ polyamide-6 blends. Polymer, 37, 2615-2626 (1996). DOI: 10.1016/0032-3861(96)87620-8

[16] Karger-Kocsis J., Csikai I.: Skin-core morphology and failure of injection-molded specimens of impact-modified polypropylene blends. Polymer Engineering and Science, 27, 241-253 (1987). DOI: $10.1002 /$ pen.760270403
[17] Bay R. S., Tucker C. L.: Fiber orientation in simple injection moldings. Part I: Theory and numerical methods. Polymer Composites, 13, 317-331 (1992).

DOI: $10.1002 /$ pc.750130409

[18] Gupta M., Wang K. K.: Fiber orientation and mechanical properties of short-fiber-reinforced injection-molded composites: Simulated and experimental results. Polymer Composites, 14, 367-382 (1993).

DOI: $10.1002 /$ pc. 750140503

[19] Cintra J. S., Tucker C. L.: Orthotropic closure approximations for flow-induced fiber orientation. Journal of Rheology, 39, 1095-1122 (1995).

DOI: $10.1122 / 1.550630$

[20] Greene J. P., Wilkes J. O.: Numerical analysis of injection molding of glass fiber reinforced thermoplastics. Part 2: Fiber orientation. Polymer Engineering and Science, 37, 1019-1035 (1997).

DOI: $10.1002 /$ pen.11747

[21] Choi W. J., Kim S. C.: Effects of talc orientation and non-isothermal crystallization rate on crystal orientation of polypropylene in injection-molded polypropylene/ethylene-propylene rubber/talc blends. Polymer, 45, 2393-2401 (2004).

DOI: $10.1016 /$ j.polymer.2004.01.058

[22] Papathanasiou T. D.: Flow-induced alignement in injection molding of fiber-reinforced polymer composites. in 'Flow-induced alignment in composite materials' (eds.: Guell D. C., Papathanasiou T. D.) Woodhead, Cambridge, 112-165 (1997).

[23] Obata Y., Sumitomo T., Ijitsu T., Matsuda M., Nomura T.: The effect of talc on the crystal orientation in polypropylene/ethylene-propylene rubber/talc polymer blends in injection molding. Polymer Engineering and Science, 41, 408-416 (2001). DOI: $10.1002 /$ pen. 10738

[24] Zhang M., Xu J., Zhang Z., Zeng H., Xiong X.: Effect of transcrystallinity on tensile behaviour of discontinuous carbon fibre reinforced semicrystalline thermoplastic composites. Polymer, 37, 5151-5158 (1996). DOI: 10.1016/0032-3861(96)00341-2

[25] Pukánszky B., Belina K., Rockenbauer A., Maurer F. H. J.: Effect of nucleation, filler anisotropy and orientation on the properties of PP composites. Composites, 25, 205-214 (1994). DOI: 10.1016/0010-4361(94)90018-3

[26] Norman D. A., Robertson R. E.: The effect of fiber orientation on the toughening of short fiber-reinforced polymers. Journal of Applied Polymer Science, 90, 2740-2751 (2003).

DOI: 10.1002/app.12913

[27] Bernasconi A., Davoli P., Basile A., Filippi A.: Effect of fibre orientation on the fatigue behaviour of a short glass fibre reinforced polyamide-6. International Journal of Fatigue, 29, 199-208 (2007).

DOI: $10.1016 /$ j.ijfatigue.2006.04.001 
[28] Fu S-F., Lauke B.: Effects of fiber length and fiber orientation distributions on the tensile strength of shortfiber-reinforced polymers. Composites Science and Technology, 56, 1179-1190 (1996).

DOI: 10.1016/S0266-3538(96)00072-3

[29] Díez-Gutiérrez S., Rodríguez-Pérez A., De Saja J. A., Velasco J. I.: Heterogeneity and anisotropy of injection-molded discs of polypropylene and polypropylene composites. Journal of Applied Polymer Science, 77, 1275-1283 (2000).

DOI: $10.1002 / 1097-4628(20000808) 77: 6<1275:: A I D-$ APP12>3.0.CO;2-P

[30] Kunkel F., Becker F., Kolling S.: Mechanical characterization of talc particle filled thermoplastics. in '8. Europäische LS-DYNA Anwenderkonferenz. Strassburg, Frankreich', p14 (2011).

[31] Hartl A. M., Balasooriya W., Reiter M., Lang R. W., Schossig M., Jerabek M.: Comparison of methods to characterize damage onset in short glass fiber filled polypropylene. in 'Proceedings of the ICCM19, Montreal, Canada' 2546-2551 (2013).

[32] Gedde U. W.: Polymer physics. Chapman and Hall, London (1995).

[33] Hermans P. H., Hermans J. J., Vermaas D., Weidinger A.: Deformation mechanism of cellulose gels. IV. General relationship between orientation of the crystalline and that of the amorphous portion. Journal of Polymer Science, 3, 1-9 (1948).

DOI: 10.1002/pol.1948.120030101

[34] Sedighiamiri A., Senden D. J. A., Tranchida D., Govaert L. E., van Dommelen J. A. W.: A micromechanical study on the deformation kinetics of oriented semicrystalline polymers. Computational Materials Science, 82, 415-426 (2014)

DOI: 10.1016/j.commatsci.2013.09.068

[35] Salaberger D., Kannappan K. A., Kastner J., Reussner J., Auinger T.: Evaluation of computed tomography data from fibre reinforced polymers to determine fibre length distribution. International Polymer Processing, 26, 283-291 (2011).

DOI: $10.3139 / 217.2441$

[36] Jerabek M., Major Z., Lang R. W.: Strain determination of polymeric materials using digital image correlation. Polymer Testing, 29, 407-416 (2010). DOI: 10.1016/j.polymertesting.2010.01.005
[37] Hornsby P. R.: Rheology, compounding and processing of filled thermoplastics. in 'Mineral fillers in thermoplastics I' (eds.: Jancar J., Fekete E., Hornsby P. R., Jancar J., Pukánszky B., Rothon R. N.) Springer, Berlin, Vol 139, 155-217 (1999).

DOI: $10.1007 / 3-540-69220-74$

[38] Advani S. G., Tucker C. L.: The use of tensors to describe and predict fiber orientation in short fiber composites. Journal of Rheology, 31, 751-784 (1987). DOI: $10.1122 / 1.549945$

[39] Advani S. G., Tucker C. L.: A tensor description of fiber orientation in short fiber composites. in 'Proceedings of the ANTEC' 85 Annual Technical Conference, Washington, USA, 1113-1118 (1985).

[40] Delhaye V., Clausen A. H., Moussy F., Othman R., Hopperstad O. S.: Influence of stress state and strain rate on the behaviour of a rubber-particle reinforced polypropylene. International Journal of Impact Engineering, 38, 208-218 (2011).

DOI: $10.1016 /$ j.ijimpeng.2010.11.004

[41] Hempel P., Seelig T.: Talcum particle modified thermoplastics, Part II: Computational modeling. in '13. Problemseminar: Deformation und Bruchverhalten von Kunststoffen, Merseburg Germany’ p8 (2011).

[42] Rijsdijk H., Contant M., Peijs A.: Continuous-glassfibre-reinforced polypropylene composites: I. Influence of maleic-anhydride-modified polypropylene on mechanical properties. Composites Science and Technology, 48, 161-172 (1993).

DOI: 10.1016/0266-3538(93)90132-Z

[43] Thomason J. L., Vlug M. A.: Influence of fibre length and concentration on the properties of glass fibre-reinforced polypropylene: 1 . Tensile and flexural modulus. Composites Part A: Applied Science and Manufacturing, 27, 477-484 (1996).

DOI: $10.1016 / 1359-835 X(95) 00065-A$

[44] Jerabek M., Major Z., Renner K., Móczó J., Pukánszky B., Lang R. W.: Filler/matrix-debonding and micromechanisms of deformation in particulate filled polypropylene composites under tension. Polymer, 51, 2040-2048 (2010).

DOI: 10.1016/j.polymer.2010.02.033

[45] Bailey E., Holloway J. R.: Experimental determination of elastic properties of talc to $800^{\circ} \mathrm{C}, 0.5 \mathrm{GPa}$; Calculations of the effect on hydrated peridotite, and implications for cold subduction zones. Earth and Planetary Science Letters, 183, 487-498 (2000).

DOI: $10.1016 / \mathrm{S} 0012-821 \mathrm{X}(00) 00288-0$ 